\title{
Commentary: Per oral endoscopic myotomy: Quite hard to swallow for thoracic surgeons!
}

\author{
Pascal-Alexandre Thomas, MD, FECTS
}

\footnotetext{
From the Department of Thoracic Surgery, North Hospital, Aix-Marseille University, and Assistance Publique-Hôpitaux de Marseille, Marseille, France.

Disclosures: Author has nothing to disclose with regard to commercial support.

Received for publication Dec 11, 2018; accepted for publication Dec 11, 2018; available ahead of print Jan 11, 2019.

Address for reprints: Pascal-Alexandre Thomas, MD, FECTS, Department of Thoracic Surgery, North Hospital, Aix-Marseille University, and Assistance Publique-Hôpitaux de Marseille, Chemin des Bourrely, 13915 Marseille, France (E-mail: pathomas@ap-hm.fr).

J Thorac Cardiovasc Surg 2019;158:952

$0022-5223 / \$ 36.00$

Copyright $\subset 2018$ by The American Association for Thoracic Surgery

https://doi.org/10.1016/j.jtcvs.2018.12.033
}

Ten years after the first per oral endoscopic myotomy (POEM) was performed on human patients, POEM is established as a safe and effective treatment for achalasia, and is now challenging conventional laparoscopic myotomy as the first-line option. The absence of randomized, controlled trials comparing the 2 procedures, however, disallows the acceptance of POEM as the gold standard. Therefore, tailored approaches and individualized indications sound good for daily practice as advocated and reported by Raja and colleagues. ${ }^{1}$ The esophageal team at Cleveland Clinic constructed a reasonable therapeutic algorithm and defined those specific subcategories of patients who would be optimally treated by POEM or surgery. Accordingly, the authors demonstrate that short-term palliation of symptoms was excellent, with a more rapid return to activities of daily living relative to coelioscopic Heller myotomy. Even in the absence of long-term assessment, which remains uncertain because of abnormal esophageal acid exposure, several subsets of patients seemed to clearly benefit from POEM compared with Heller myotomy. The authors conclude judiciously that POEM is an important but not exclusive option for the treatment of achalasia, positioned between pneumatic dilatation/endoscopic botox injection and Heller myotomy plus fundoplication.

The authors also acknowledge that the procedure, the learning curve for which reached its plateau at about 100 cases, requires extensive training in advanced endoscopy. Indeed, advanced esophageal endoscopy is among the disruptive technological innovations thoracic surgeons must assimilate. In general, innovation leads to regionalization of patients' referral to expert centers with dedicated multidisciplinary teams composed of overspecialized physicians and surgeons. Many aspects of our specialty are developing consistently, and that trend begs questions about how to train and mold the thoracic surgeons of tomorrow.

\section{Reference} 2019;158:945-51.

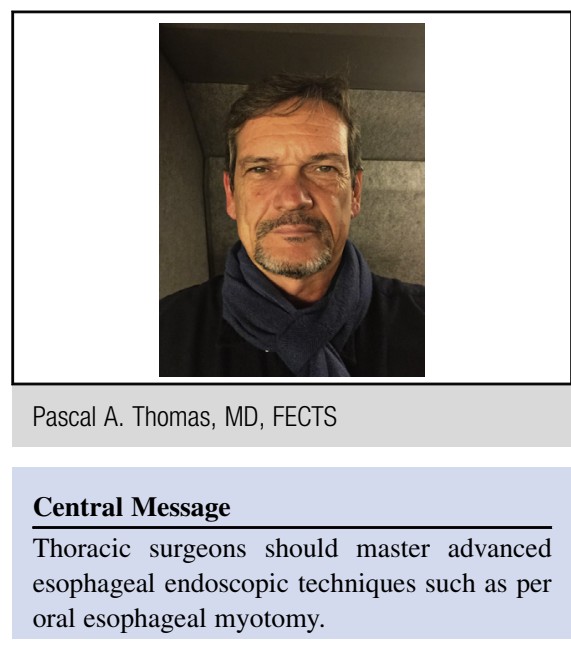

See Article page 945

The present report fuels the belief that thoracic surgeons should gain control of advanced esophageal endoscopic techniques, as he or she should do with tracheal-bronchial endoscopic procedures allowing localizing and destroying some early-stage lung cancers, or percutaneous endovascular approaches to cardiac valve replacement and aortic stenting. According to the shared decision-making process in any situation where the choice of a treatment option might be best made at the individual patient level, all patients should be informed about the advantages and disadvantages of each. The best means to achieve this goal is that the same individual provides the information-the thoracic surgeon being the right person for the job because only thoracic surgeons are able to deal with the most severe complications of these minimally invasive techniques and to offer surgical alternatives. He or she would be also the most motivated and proficient person to recruit patients into randomized studies that aim to ascertain the place of each option in the whole spectrum. Thus, thoracic surgeons should master esophageal endoscopic techniques such as POEM. Otherwise, POEM would be a supplemental challenge that would be very hard to swallow.

1. Raja S, Murthy SC, Tang A, Siddiqui HU, Parikh MP, Ahmad U, et al. Per oral endoscopic myotomy: another tool in the toolbox. J Thorac Cardiovasc Surg. 